\title{
Peritoneal Multicystic Mesothelioma
}

National Cancer Institute

\section{Source}

National Cancer Institute. Peritoneal Multicystic Mesothelioma. NCI Thesaurus. Code C6536.

A cystic mesothelioma that arises from the peritoneum and usually affects young to middle aged females. Grossly, it presents as a large multiloculated tumor mass, usually in the pelvic peritoneum. Histologically it is characterized by the presence of multiple cysts that are lined by one or more layers of mesothelial cells that do not show atypia. Patients usually present with abdominal or pelvic mass and pain. The clinical course is indolent. The tumor may recur, but transformation to diffuse malignant mesothelioma is rare. 